Seeing New in the Familiar: Intensifying Aesthetic Engagement with the City through New Location-Based Technologies

\title{
Lehtinen, Sanna
}

2020

Lehtinen , S \& Vihanninjoki , V J 2020 , ' Seeing New in the Familiar: Intensifying Aesthetic

Engagement with the City through New Location-Based Technologies ' , Behaviour \&

Information Technology, vol. 39 , no. 6 , pp. 648-655 . https://doi.org/10.1080/0144929X.2019.1677776

http://hdl.handle.net/10138/320454

https://doi.org/10.1080/0144929X.2019.1677776

acceptedVersion

Downloaded from Helda, University of Helsinki institutional repository.

This is an electronic reprint of the original article.

This reprint may differ from the original in pagination and typographic detail.

Please cite the original version. 


\section{Seeing New in the Familiar:}

\section{Intensifying Aesthetic Engagement with the City through New Location-Based Technologies}

Sanna Lehtinen (corresponding author)

University of Helsinki, Finland

sanna.t.lehtinen@helsinki.fi

Vesa Vihanninjoki

University of Helsinki, Finland

vesa.vihanninjoki@helsinki.fi 


\section{Short Abstract (196 words)}

Understanding better the effects of the use of mobile apps to the use and appreciation of urban environments has been gaining more prominence as a research topic recently due to the increasing everyday use of these apps. Whether this type of digital mediation changes the lived experience is of interest in this article. The intention is to show, that besides changing the prevailing practices and behaviour, new technologies also enhance and add positive value to the everyday urban experience. This positive experiential value is approached with the framework consisting of recent advances in philosophical urban and everyday aesthetics, which put emphasis on both familiarity and fun as important qualities that describe the everyday experience in urban environments. We claim, that new digital tools increase the quality of fun when moving in familiar surroundings. Fun, understood through the lens of the aesthetic, precedes the experienced quality of playfulness. It alters the existing affordances of the urban environment in a way, that make more complex aesthetic qualities emerge. The case examples are GPS-based wayfinding applications such as route planners and navigation tools for pedestrian use but and related AR applications such as the popular game app Pokémon Go.

\section{Keywords:}

Urban Aesthetics, Everyday experience, Familiarity, Fun, Playfulness, Wayfinding, Pokémon Go

\section{Total Word Count: 5465}

\section{Introduction}

The neologism "technoference" has been used recently to describe for example the decreased quality of interhuman relations due to the increased use and reliance on mobile devices (e.g. McDaniel 2015). How this type of reliance is affecting the use and perception of urban space, has still been less studied. However, it is clear that this type of absent-mindedness caused predominantly by increased technological mediation has become already an urban trope causing amusement and irritation in equal amounts. Seeing a place through one's screen is lamented to diminish the quality of the lived experience of that particular place. People walking on city streets while staring at their mobile devices has given rise to the derogatory term "smartphone zombie" or "smombie" in the contemporary urban culture (e.g. Chatfield 2016). Even though the users of mobile devices are physically present in the place, they seem to be less present and alert mentally in the situation, as the mobile device is indisputably at the focus of attention.

Acknowledging the potentially dangerous consequences of this new type of urban behaviour, it is of interest to understand in a more comprehensive way what exactly happens to the subjectively experienced engagement with urban places when they are increasingly perceived through their on-screen representations yet, at the same time, being physically present in them. This has become an especially important topic with the rapid increase in ubiquitous reliance on contemporary mobile route planning and wayfinding applications, which are designed to guide their users as smoothly and efficiently as possible from point $A$ to point $B$. 
The aim in this article is to show how philosophical urban everyday aesthetics could be used as a theoretical framework to study how the consequences of adding this layer of "screen value" to experiential value of a place could be evaluated. Our hypothesis is that this change in behaviour does not need to be understood necessarily only as a threat to the more traditional understanding of the lived experience. The currently used new mobile technologies do not intrinsically alienate or detach the users from their most immediate physical surroundings. While this hypothesis is also backed up by research in mobile interface studies (e.g. De Souza e Silva \& Frith 2012) the prejudices towards some recent advances in mobile interfaces defend the need to re-examine the topic also with new perspectives. With this hypothesis as the starting point, GPSbased technologies and the wider effects of their use might be studied in a more comprehensive way, taking cue also from the recent advances in humanistic and philosophical studies of the urban environment. We argue, for example, that based on recent research done in the context of everyday aesthetic values, the use of mobile location-based technologies can also enhance and add positive value to the experiential qualities of the urban environment. In order to study this further, we bring together how the notion of "fun" has been treated as an aesthetic quality of everyday life (mainly by Thomas Leddy) and, on the other hand, how this definition of fun as an indispensable everyday aesthetic quality can help to assess some of the new, more complex forms of playfulness that stem from the technology-mediated engagement with the otherwise familiar urban environment.

As the theoretical framework coming mainly from the sphere of philosophical urban and everyday aesthetics does not discuss technology to any significant degree, the postphenomenological approach to philosophy of technology as well as some recent strands in affordance theory have been indispensable for building the main arguments of this article. This article seeks to complement the recent studies in psychology (e.g. Dalton et al. 2019), social studies (e.g. Leorke 2019) and visual culture (e.g. Dibazar \& al. 2019) which have shed light on how contemporary mobile technologies are changing how the city is perceived, experienced and further imagined and interpreted. A selection of recent GPS-based wayfinding applications such as route and journey planners and location-based AR games such as Pokémon GO have been used as references informing the current state of these widely-used technologies. The article aims at conceptualizing how they enrich the urban experience with previously inhibited but now newly available opportunities for a wider variety of different types of aesthetic experiences, leading ultimately to an increase also in the creative use of urban space. Understood in this way, the use of mobile apps may enhance the aesthetically perceived value of the place even in the most familiar everyday environments.

\section{New Wayfinding Practices in the Urban Environment}

New wayfinding tools and the practices related to their use contribute in various ways to increasing the general accessibility of urban environments: previously unnoticed places become known and more alluring through their on-screen representations, route planners offer route options that we 
would not have otherwise considered and so on.1 Navigation apps relying on Global Positioning System (GPS) consist of a wide range of route planners and wayfinding apps, but also increasingly of mobile augmented reality (AR) games which integrate features from virtual and physical environments. These tools and games are gaining importance through mediating experience and engagement with the physical surroundings especially in the context of the everyday. For the purpose of this article, we have chosen to focus on the community-based route planner app Waze, walking directions in Google Maps, and on the Helsinki metropolitan area Journey Planner, which provides the official app by the Helsinki Region Transport Authority. We have been studying and using these apps within familiar urban environments and rely also on various empirical studies made with their users (e.g. Hunter \& al. 2016; Ishigawa 2016). The use and features of the chosen apps has been compared with the currently popular mobile game Pokémon Go, which employs the same location-based technology for gaming purposes.

Prevalent forms of human mobility within the urban context are understood to be changing due to the rise of new technologies, but without unanimity about the exact amount and desirability of this change. Spatial thinking as such is feared to be at risk due to the over-reliance on navigation apps. (e.g. Grabar 2014) The transformative effect of new wayfinding tools is feared to take even evolutionary dimensions, starting to erode the human capacity to think and, as a consequence, to act spatially in a conscious and efficient way. It has been also widely suspected, that the ubiquitous and skilful use of digital tools has far-reaching consequences for the relation with the physical environment: "The habits, hubris, and quirky predilections that once manipulated my movements are being replaced by the judgments of artificial intelligence." (Grabar 2014). As a result, the notoriously erratic human behaviour might become more rationalized or, in any case, more directed by extrinsic factors based on algorithms opaque to the end users of the apps.

Formally, the visual guidance provided by the currently used mobile app interfaces does not differ radically from that of portable paper maps. However, one clear difference from the user's perspective is acquiring the possibility of locating oneself reliably on the map at any given moment in time. With paper maps, locating oneself is one of the most difficult tasks and also the crucial moment when the physical surroundings and its two-dimensional representation in the map format are most clearly put into interaction through interpretative activity. Thus, contrary to the most negatively inclining scenarios, it could be argued based on implementation of previous navigation tools such as paper maps, that a gradual shift is a more likely alternative to disruptive change in this case. However, these various scenarios also in themselves attest that new mobile technologies seem to unleash previously unrealized possibilities in experiencing environments. This could refer to freedom of attention as much as to freedom of movement.

The consequences of new wayfinding practices, especially those relying on smart location-based technologies, may encourage creativity and playfulness in the use of city space through experiences definable as "fun". It is important to note, that in its current modes, wayfinding is also a social practice to a considerable extent, the psychology and behaviour behind which has been also recently studied (e.g. Dalton et al. 2019). There are two interesting lines of progression taking place currently in the individual, aesthetic experience of the urban environment, in both of them technology acts as an overall agent of change (Lehtinen \& Vihanninjoki 2019). First, something that can be described as the aesthetic approach to the environment is currently more possible and even likely to take place than previously, since the GPS technologies make us less reliant on the conventional locational markers and features of the environment. On the other hand,

\footnotetext{
${ }^{1}$ It is important to take into consideration, that there are also crucial limitations to the use of mobile apps, for example in militarized or politically controversial areas. Some large-scale extreme examples include Palestine, Gaza, and North Korea.
} 
GPS-based wayfinding-related apps such as Pokémon Go make us see completely new placebased affordances in the environment, giving potentially rise to entirely new forms of sense of place (Lehtinen \& Vihanninjoki 2019).

Smartphone-based wayfinding practices might thus seem to support the specific type of attention that has been in traditional aesthetic theories been described as aesthetic attitude towards one's surroundings: more intent and free forms of observation and experience are possible, as one can safely let go of the constantly present task of locating oneself geographically. In this paper we have set out to speculate in which ways the place value and the lived experience develop when smartphones are used in urban wayfinding, particularly when one moves on foot in an urban environment. Experience of the city is understood here as a socio-culturally built set of conditions but also as an embodied, sensorially based and situated condition which is thus part of the intrinsically subjective realm. Embodiment in itself, is always already a spatial practice (Farman 2012). In general, besides increased focus on the details, also the city as a large-scale system is probably gaining a new form of aesthetic appreciation, where functional and overflowing features all contribute to the diversity of the city and to the experience of it.

Pokémon Go as an AR game integrates virtual and physical environments. It is played with the mobile phone, most often in similar urban settings where wayfinding applications are used. The purpose for playing a game instead of finding a route from point $A$ to point $B$ is based on different intentions. Pokémon Go engages its player into a scavenger hunt in the urban space. Playing it is very much focused on areas which are already used to a great extent. More quiet areas of the city might not be that good for playing the game, but even in the most popular areas, game directs the attention of its players to previously unnoticed features of the environment. An architectural ornament, memorial plate, statuette, or any visibly notable feature might gain new importance through the "lens" of the game. In order to play the game, one is not required to know the place where one is playing it: Pokémon Go might be played at one's everyday environment as well as in places which one is visiting as a tourist. For the purposes of this article, we focus on those occasions, when the game is played in the familiar everyday environments.

Since its release in July 2016 Pokémon Go2 has gained both positive and negative attention. Playing the game has been the main cause of some accidents, which has lead experts to exhibit worry over how the AR qualities of the game "present genuine dangers especially to the more vulnerable, often easily distracted pediatric population" even though admitting at the same time that "Pokémon GO can be a fun and entertaining game that encourages smartphone users of all ages to be active outside their homes, often outdoors, in order to explore and play." (Raj, Karlin \& Backstrom 2016) There are already numerous psychological studies on the behavior or even the personality features of Pokémon Go players (e.g. Khalis \& Mikami 2018; Tabacchi, Caci, Cardaci \& Perticone 2017). However, more diverse analyses of the relation to the environment within which the play takes place, seem to be missing in research literature.

The seamless continuity of the virtual and the physical environment is the goal in these types of mobile AR games. The hypothesis is, that these relatively new location-based apps enable a new type of aesthetic interest towards the existing but unacknowledged qualities and features of the physical surroundings. This change in interest follows from how attention gets directed in more free and creative ways while engaged with the familiar environment in new, exciting and fun ways. As the intricacies of the interface qualities of these new modes of play are studied more closely in the field of human-computer interaction $(\mathrm{HCl})$, it is still less clear in which ways the interaction with the new urban location-based technologies alters the relation with other

\footnotetext{
2 Harry Potter: Wizards Unite, a game which was launched on 21 June 2019 is clearly aimed at a wide audience similarly to Pokémon Go, Niantic's previous success game.
} 
components in the environment. Collateral consequences of using a particular technology are difficult to trace and this is why we are resorting to tools from a more speculative tradition of thinking in the form of philosophical aesthetics.

\section{Technologically mediated urban experience understood through aesthetic engagement}

In various disciplines, and even further in inter-and multidisciplinary constellations, there has been increasingly emphasis and urge on making sense of the technology-induced changes in the urban experience. How the urban experience is mediated by technologies could be in many ways, but the most obvious dimension is often easiest to neglect. How many new urban technologies affect end up affecting the individual urban user is through the effect they have on the sensory and perceptual realm of the experience. Several new mobile technologies that have been adopted into the everyday use, for example, require intricate visual or visuo-spatial interpretation skills. This emphasis on perceptual capacities links these new technologies into the realm of the aesthetic in urban experience, aesthetics understood here as the study of subjective and sensori-emotional values. The aesthetic referring to this perceptual layer of the human existence has also uncontested but easily neglected epistemological value. Or, simply put: on an individual level, we get information about our surroundings through our senses in a complex process where it already gets mixed up with our previous knowledge and experiences, beliefs, expectations, cognitive biases, memories, emotions and imagination. The aesthetic is not used here in an evaluative sense (as a synonym for the beautiful for example) but as a grounding mode of the human experience.

Philosophical urban aesthetics focuses on studying to what extent and in which ways urban environments are experienced aesthetically and how these experiences could help in developing methods for qualitative assessment of urban environments. Aesthetic engagement has been established into the terminology or environmental aesthetics following from John Dewey's pragmatist philosophy. (Blanc 2013) Engagement explains in this context, not only how one interacts with the environment, but also including in this more strongly the embodied, multimodal and experientially evolving, mode of being present in connection with the surroundings. (e.g. Berleant 2007; Berleant \& Carlson 2007) The urban environment is particularly interesting with aesthetic engagement in mind, since current global-scale megalopolises, for example, are dense with sensory stimuli and different types of perceptually-cued affordances. This abundance of possibilities for experiential richness is also something, which might prove to be problematic: for example, if the excess of too many perceptually ambiguous high-level stimuli becomes unbearable. Advertisements, street signs, excessive traffic, other people and the overall look (e.g. chaotic, unorganized) or architectural elements (too diverse) of a part of a city has all been considered to contribute to this type of undesirable aesthetic overabundance and negatively experienced incoherence (e.g. Kolhonen 2005; von Bonsdorff 2008).

There has been substantial emphasis in literature on aesthetics of the urban environment on the importance of familiarity for the aesthetic engagement with a place (e.g. Haapala 2005; Haapala 2017; Saito 2017). Arto Haapala's view, for example, puts "forward an existential account of the phenomenon of the everyday and its aesthetic character." (Haapala 2005,39 .) This focus on the existential importance of the everyday emphasizes its familiar, experiential qualities. Aesthetics in this account refers to the human modes of acquiring and 
processing information about the world through the physical features of the particular environment in question. Since Haapala is focused on the everyday, the environment in question is that in which the everyday life takes place. For most people living currently and in the foreseen future on the planet Earth, the everyday life is equal to urban life. This urban way of living in turn, despite the obvious differences in cities, shares many elements and is thus comparable to a reasonable extent. These globally shared urban elements include phenomena such as the denseness of the built environment, proximity of other people and, increasingly, habituated use of refined and shared technologies.

Whereas Haapala focuses on studying the familiar spatial sphere of the everyday through the notion on place, the focus here is on what repercussions this type of thinking has for our understanding of the city at large. The city as the main "arena" for the everyday encompasses both more and less familiar areas as well as places that we know well only through the news, stories, and other people but rarely visit ourselves. The city also provides us with the unique yet quintessentially urban places that serve as starting points for our individual excursions into the city. Place is one useful concept in understanding this, since it is part of the common parlance, easy to grasp even though difficult to fully define. As Haapala points out, expressions such as "sense of place" refer strongly to the "senser": there is always someone to sense, perceive, and interpret the place in question (Haapala 2005). This link to the experiential quality of urban space through the notion of the sense of place is central to our understanding of how new mobile apps are changing the underlying assumptions of how the physical qualities of the environment become or could and should become experienced.

In a passage on a sense of place, Haapala refers to Norberg-Schulz' well-known formulation of genius loci, according to which environmental character as the essence of place comprises "concrete things having material substance" (Norberg-Schulz 1980). It seems now inevitable to add, that contemporary technologies are adding another layer to these physical features of the environment. How this process takes place and how these new elements become experienced needs further study. It seems clear, that on the level of subjective experience, the effects of technologically induced change in experiencing urban environments can also be dealt with through speculative practices such as different forms of play. The urban everyday is not only the realm of logical and rational efficiency but also open to the human qualities such as emotions, imagination, and different types of unanticipated quirks. When it comes to these examples of "the human factor", wayfinding technologies might induce more experiential variety in the already familiar urban environments since the need for rational attention for finding one's way is already less acutely present.

It seems obvious why location-based apps are needed in unfamiliar and new places and they have proven indispensable to those, who are visiting urban places. However, people use navigation apps in familiar environments for a much wider variety of reasons: navigation is needed in order to optimize and compare the already established routes, new route required by everyday activities starts from familiar settings, and apps are used also to increase the understanding of the spatial layout of their neighbourhoods. Cartographic literacy is on the rise due to the extensive use of contemporary navigation aids. (Grabar 2014) Especially in the new global metropolises, it might be difficult to find new addresses even in already familiar environments due to the density of these environments and the rapid pace of development. Location-based apps are also used increasingly for purposes of play and entertainment. The gamification trend within the familiar urban environment relies of fast-developing AR technologies and the new application possibilities are fascinatingly altering the way the most mundane elements of the familiar surroundings are seen. Games such as Pokémon Go encourage to spend time outdoors near home, and already this increased time in itself can prove to bring new facets out of the familiar places. The activity of 
mobile gaming provides an acceptable reason to stay and linger - hang out - in places that one has previously only passed by.

Besides these new indirect ways in which the new technologies affect the relationship with the familiar environment - closer study of existing routes, lingering in new places, increasing cartographic literacy - technological mediation 3 also seems to add something on a more fundamental and perceptual level to the elements of the everyday environment. Whether it is through a new way of representing a familiar place through computer-generated images (as in route planners) or pointing attention to previously unnoticed elements of the environment, this effect seems to be more fundamental in affecting the urban everyday experience and goes at least partially beyond how these technologies are planned in the first place. In this way, navigation technologies that are applied and used in the contemporary everyday act also as catalysts producing heightened attention regarding the aesthetically manifested values in the environment. Technological mediation in the form of these navigation tools make us look at the environment in a different way, not only when using these tools but also when strolling the familiar city streets without them. What is ultimately missing from these technologies, is, however, the multimodality of the experience. Their use is based on the multisensory qualities of the "original" physical environment in which they are used: the smells and both haptic4 and auditory qualities mostly come only from the actual physical surroundings in which these apps are used. Their use thus always necessarily merges with the elements of the concrete environment. The possibilities of this type of augmented engagement makes these technologies all the more interesting from the perspective of urban aesthetics.

\section{Elements of fun in the technologically mediated familiar environment}

When it comes to the everyday life, joyful instances have not been traditionally at the forefront of research interest. The notion of the everyday itself seems to direct thoughts towards the functionally important, mundane tasks and chores or the habitually executed routines that belong to the inescapable realm of the everyday (Naukkarinen 2013). This kind of emphasis on the "serious" and pragmatic features of the everyday has been predominant also in the study of the urban everyday. Whether leisure time and activities described with notions such as fun have been dealt as secondary due to the internal rational logic of more developed human societies, or, because fun and play as such are still often considered to be the domain of children - although interesting topics as such - are not in the scope of our inquiry here. However, it is worth to notice that how the city has been conceptualized for planning purposes has also focused on optimizing the use and predictability of the functional elements of the city. Efficiency is a well-recognized value for example in transportation planning, but there has been surprisingly little interest in studying the ensuing experienced quality of this efficiently used quotidian time (Mladenovic \& al. 2019).

The negligence of perceiving "fun" as an aesthetic category of interest in explaining human behaviour or values is to a certain extent due to it being interpreted as a predominantly hedonistic mode of experience. However, this lack has been alleviated by some recent advances in aesthetic theory, which (besides the sphere of art or entertainment) place fun into the core of those basal level aesthetic categories that characterize the everyday experience. The recent

\footnotetext{
${ }^{3}$ The theory of technological mediation that we rely on in this context comes from postphenomenological approach to philosophy of technology (e.g. Verbeek 2005).

${ }^{4}$ Some apps use also haptic cues such as vibration to alert the users of certain features of the app.
} 
emphasis on aesthetics of the everyday has changed this and has brought to the discussion some concepts which have been previously considered too frivolous or otherwise of minor importance. In his account of aesthetics of everyday life, Thomas Leddy goes through the terminology relating to aesthetic experiences within the sphere of the everyday. "Fun things might best be seen as a subset of things that are liked or pleasant. The word 'fun' is strongly associated with jokes and jocularity, but you can have fun without laughter. [...] The concept is also of great importance in the aesthetic lives of children and teens, and continues as a somewhat less important aspect of adult aesthetic experience." (Leddy 2012, 152)

"The term 'fun' is applied mainly to activities, for example play, amusement, and entertainment, although it may also be applied to things, for example jokes." (Leddy 2012, 153) Fun as a concept implying on activities in the urban environment seems thus to imply unconventional use of the city space. This activity in itself might be extraordinary (such as in the case of a parade), or it might be unconventional within a particular set of everyday habits. "Fun" has not been considered traditionally a very valuable term for describing the human experience in other than the spheres or environments dedicated to play or entertainment specifically. The bestknown examples come from commercialized entertainment environments such as amusement parks or activity parks. Everyday environments, on the opposite hand, are characterized through concepts such as practicality, functionality, and efficiency. Familiar, everyday environments might not indeed be the obvious places for intriguing a sense of curiousness or adventure. However, the new layers of experiential affordances opened by location-based technologies might be changing this significantly. There are studies on how such practices as parkour or "hanging out" contribute to the aesthetics and creative use of urban space (Tani 2014; Ameel \& Tani 2012; Pyyry), but the increase in the use of GPS-based mobile applications would need to be further studied from the perspective of re-evaluation of the experiential horizon of previoualy familiar urban places.

'Fun' is "a quality of an activity that involves pleasure". It also "fits the broadest definition of the aesthetic, the one that defines beauty as pleasure gained in the mere apprehension of something." (Leddy 2012, 153-154.) Emphasis on the aesthetic experience means also emphasizing the immediacy of experiences. Technological mediation makes the notion of immediacy more somewhat more complex, but nonetheless the experiential process develops in a similar way. Defined in this way, fun implies a range of creative flexibility in immediate experiences. In the case of urban aesthetic experience, this could refer to how the traditional qualities of urban environment are perceived and experienced in a new light or the experience of fun might stem from some entirely new form or quality present in the familiar context. The range of "fun" yields also from the mildly amusing to that which is on the verge of full-blown absurdity.

According to Leddy, "to say that something or some experience is fun can mean that it has a heightened significance, that it is more alive, that it seems to emanate meaning, and so forth." (Leddy 2012, 154) This type of definition would seem to support the idea, that the experiences in the urban space that one would describe as fun are also symptomatic of a heightened attention towards the features of the surroundings. Leddy does not distinguish between the sources of these kinds of experiences in the everyday and neither is technology mentioned explicitly. In this sense, we are left to wonder, how technological mediation affects everyday experiences. All in all, technology is surprisingly little discussed in the main discussions on everyday aesthetics. This avoidance might be due to lack of knowledge about technology or because it is still seen as a hindrance and a form of alienation from the more authentic experiences that would take place without the use of technologies. This, however, is proving to be an increasingly problematic idea and in order to gain deep understanding of the aesthetics of the everyday, the theme of technology has to be introduced into the field of everyday aesthetics. 
More flexible ways of using urban space have undeniably emerged during the last decades in the context of developed cities globally. This is also the result of changing social norms such as the development towards increase in gender equality. Especially interesting from the perspective of aesthetics is, how the new forms of urban technologies can lead to increased possibilities of self-actualization in the urban environment. Self-actualization is here understood widely as the realization or fulfilment of one's creative or otherwise internally motivated talents and potentialities. This is considered to be a drive or need common and shared to a certain degree by all individual human beings. Games have traditionally provided a medium and new opportunities for experimentation by providing a "magic circle" in which new roles, rules and opportunities for actions have been possible (Nguyen 2017). AR games are also forerunners in the use of new technologies and it is likely, that many of the features that will define future urban wayfinding tools have first been experimented in the form of AR and advanced geospatial games.

The confluence of these particular technologies and the physical urban environments where they become used can from the vantage point of aesthetic analysis be seen as a moment for re-evaluation of the engagement with these environments. Whether new technologies enhance and reinforce the already existing forms of engagement, or whether they open up new possibilities is of interest also because these effects might have serious consequences not only for the use but also for the planning of urban environments.

It is possible to argue, that urban dwellers especially in the affluent societies of the Global North have become able and more prone to appreciate urban environments through their distinctive aesthetic qualities that are not directly related to finding one's way in the city. This brings certain other types of unobtrusive or "tacit" aesthetic qualities of the environment into focus also in the relation one has with various urban places - that is, compared to the locational qualities related to mere place identification. The argument is based on the fact that one does not depend anymore solely on the information provided by e.g. roads and buildings to tell us where we are in a city: urban landscape or topography can cease to function principally as the guiding features in an environment. Instead, they are seen full of new possibilities, opportunities fuelled by their aesthetic potentiality or the inner logic of the game.

\section{Conclusions}

The aim of this conceptually focused article has been to describe how the increased use of mobile apps for navigation purposes is adding elements of fun and playfulness to the engagement with the familiar urban everyday environments. This has been done by using definitions for the aesthetic aspects of the categories of 'fun' and 'familiarity' that have been developed within the overlapping fields of philosophical urban and everyday aesthetics. The opportunities for fun and playfulness that new technologies insert into the urban everyday life have traditionally been considered difficult to assess and thus, so far, the emphasis has been on the negative effects of the everyday use of these technologies.

Fun and playfulness as experienced qualities are in one form or another present in the everyday use of urban space. However, in discussions about developing cities they often remain on an implicit level due to overemphasized focus on measurable qualities such as efficiency. Such is the case with understanding end developing human mobility in cities, for example. Human mobility should not be understood merely through the notion of transportation which relies on quantifiable determinants such as efficiency and cost-benefit analysis. Regardless 
of these traditional tendencies in urban planning, fun and playfulness are intrinsically important for attaining a more comprehensive understanding of the human experience.

As digital mobile technologies are an increasingly important part of the everyday life globally, understanding what type of experiences they enhance or suppress is of crucial importance. The theory of technological mediation and philosophical urban aesthetics have been used here to explicate the primordially fun-based nature of the playful interactions that new tools bring forth. This leads to different new hypotheses, for example it could be stated based on this that efficiency alone is not a sufficient parameter to guide the design of the smart city solutions which are aimed at the everyday use of individuals. Focus on their creative usage through the notions of fun and playfulness would significantly increase the success of implementing new solutions into the everyday. Philosophical and applied approaches to everyday urban experience provide one way of conceptualizing these inherently human qualities, which describe part of the immediate engagement with the urban environment.

\section{References}

Ameel, Lieven and Sirpa Tani. 2012. "Everyday aesthetics in action: Parkour eyes and the beauty of concrete walls". Emotion, Space and Society August 2012, Vol.5(3), pp.164-173

Berleant, Arnold. 2007. "Cultivating an Urban Aesthetic," in The Aesthetics of Human Environments, edited by Arnold Berleant, and Allen Carlson, 79-91. Toronto: Broadview.

Berleant, Arnold, and Allen Carlson, eds. 2007. The Aesthetics of Human Environments. Toronto: Broadview.

Blanc, Nathalie. 2013. "Aesthetic Engagement in the City", Contemporary Aesthetics.

Bonsdorff, Pauline von. 2008. "Urban Richness and the Art of Building", in A. Berleant \& A. Carlson (eds.), The Aesthetics of Human Environments, Peterborough: Broadview Press, pp. 66-78.

Brown, Greg, Raymond, Christopher M. \& Corcoran, Jonathan. 2015. "Mapping and measuring place attachment", Applied Geography, Vol.57, p. 42(12).

Chatfield, Tom. 2016. "The new words that expose our smartphone obsessions", Available online: http://www.bbc.com/future/story/20161129-the-new-words-that-reveal-how-tech-has-changedus (accessed June 13, 2019).

Dalton, Ruth Conroy, Christoph Hölscher and Daniel R. Montello. 2019. "Wayfinding as a Social Activity." Frontiers in psychology 10: 142.

De Souza E Silva, Adriana and Jordan Frith. 2012. Mobile Interfaces in Public Spaces. London: Routledge.

Dibazar, Pedram and Judith Naeff (eds.). 2019. Visualizing the Street: New Practices of Documenting, Navigating and Imagining the City. Amsterdam: Amsterdam University Press.

Farman, Jason. 2012. Mobile Interface Theory: Embodied Space and Locative Media. London \& New York: Routledge.

Gibson, James J. 1979. The Ecological Approach to Visual Perception. Boston: Houghton-Mifflin.

Grabar, Henry. 2014. "Smartphones and the Uncertain Future of 'Spatial Thinking'”, Available online: https://www.citylab.com/life/2014/09/smartphones-and-the-uncertain-future-of-spatialthinking/379796/ (accessed February 15, 2019).

Haapala, Arto, 2005. "On the aesthetics of the everyday: Familiarity, strangeness, and the meaning of place", in Light, Andrew, Smith, Jonathan M. (Eds.), The Aesthetics of Everyday Life. New York: Columbia University Press, pp. 39-55.

Hunter, Rebecca H., Lynda A. Anderson, and Basia L. Belza, eds. 2016. Community Wayfinding. Pathways to Understanding. Switzerland: Springer. 
Ishikawa, Toru. 2016. "Maps in the Head and Tools in the Hand: Wayfinding and Navigation in a Spatially Enabled Society," in Community Wayfinding. Pathways to Understanding, edited by Rebecca H. Hunter, Lynda A. Anderson, and Basia L. Belza. Switzerland: Springer.

Khalis, Adri, and Amori Yee Mikami. 2018. "Who's Gotta Catch 'Em All?: Individual differences in Pokèmon Go gameplay behaviors," in Personality and Individual Differences 1 April 2018, Vol.124, pp.35-38.

King, Michael R., and Elise de Jong. 2016. "Legibility and Continuity in the Built Environment," in Community Wayfinding. Pathways to Understanding, edited by Rebecca H. Hunter, Lynda A. Anderson, and Basia L. Belza. Switzerland: Springer.

Kolhonen, Pasi. 2005. "Moving Pictures - Advertising, Traffic and Cityscape," in Contemporary Aesthetics, Special vol. 1

Leddy, Thomas. 2005. "The nature of everyday aesthetics", in Light, Andrew, Smith, Jonathan M. (Eds.), The Aesthetics of Everyday Life. New York: Columbia University Press, pp. 3-22.

Leddy, Thomas. 2012. The Extraordinary in the Ordinary: The Aesthetics of Everyday Life. Peterborough, Ontario: Broadview Press.

Lehtinen, S. \& Vihanninjoki, V. 2019 (forthcoming). "Aesthetic Perspectives to Urban Technologies: Conceptualizing and Evaluating the Technology-Driven Changes in the Urban Everyday Experience", in Nagenborg, M., González Woge, M., Stone, T. \& Vermaas, P. (eds.) Technology and the City: Towards a Philosophy of Urban Technologies. Springer (Philosophy of Engineering and Technology Series).

Lehtinen, Sanna. 2015. Excursions into Everyday Spaces: Mapping Aesthetic Potentiality of Urban Environments through Preaesthetic Sensitivities. Helsinki: University of Helsinki.

Leorke, Dale. 2019. "Wayfinding and Codemaking in the City of Melbourne." Location-Based Gaming. Palgrave Macmillan, Singapore, pp. 195-240.

Madsen, Peter and Richard Plunz, eds. 2002. The Urban Lifeworld: Formation, Perception, Representation. London \& New York: Routledge.

McDaniel, Brandon T. 2015. "Technoference": Everyday intrusions and interruptions of technology in couple and family relationships. In C. J. Bruess (Ed.), Family communication in the age of digital and social media. New York: Peter Lang Publishing.

Mladenović, Miloš, Sanna Lehtinen, Emily Soh and Karel Martens. 2019. "Emerging Urban Mobility Technologies through the Lens of Everyday Urban Aesthetics: Case of Self-Driving Vehicle," Essays in Philosophy: Vol. 20: Iss. 2, Article 3. https://doi.org/10.7710/15260569.1633

Naukkarinen, Ossi. 2013. What Is 'Everyday' in Everyday Aesthetics? Contemporary Aesthetics 11.

Nguyen, C. Thi. 2017. "Philosophy of Games," Philosophy Compass, Vol. 12(8). https://doi.org/10.1111/phc3.12426.

Norberg-Schulz, Christian. 1980. Genius Loci. Towards a Phenomenology of Architecture. New York: Rizzoli.

Raj, Marc Alexander, Karlin, Aaron \& Zachary K. Backstrom. 2016. "Pokémon GO: Imaginary Creatures, Tangible Risks," Clinical Pediatrics, Vol. 55(13), pp. 1195-1196.

Raymond, Christopher M., Kyttä, Marketta, Stedman, Richard 2017. "Sense of Place, Fast and Slow: The Potential Contributions of Affordance Theory to Sense of Place”, Frontiers in psychology, Vol.8, pp.1674

Rietveld, Erik, and Julian Kiverstein. 2014. "A Rich Landscape of Affordances," Ecological Psychology 26, no. 4: 325-352.

Saito, Yuriko. 2017. Aesthetics of the Familiar: Everyday Life and World-Making. Oxford: Oxford University Press.

Sarapik, Virve, and Kadri Tüür, eds. 2003. Place and Location. Tallinn: Estonian Academy of Arts.

Tabacchi, Marco Elio, Caci, Barbara, Cardaci, Maurizio, and Valerio Perticone. 2017. "Early usage of Pokémon Go and its personality correlates," Computers in Human Behavior July 2017, Vol.72, pp.163-169.

Tani, Sirpa. 2014. "Loosening/tightening spaces in the geographies of hanging out". Social \& Cultural Geography 03 September 2014, pp. 1-21. 
Verbeek, Peter-Paul. 2005. What Things Do. Philosophical Reflections on Technology, Agency, and Design. University Park, PA: Pennsylvania State University Press.

Vihanninjoki, Vesa. 2019. "Urban Places as Aesthetic Phenomena: Framework for a Place-Based Ontology of Urban Lifeworld," Topoi. 